\title{
PHẪU THUẬT BÓC LỚP TRONG ĐộNG MẠCH CẢNH KINH NGHIỆM 500 TRƯờNG HỢP
}

\author{
Đỗ Kim Quế*, Lê Phi Long**, Phạm Phi Hùng*
}

\section{TÓM TẮT}

Đặt vấn đề: Phẫu thuật bóc lớp trong động mạch cảnh đã được chứng minh là phương pháp điều trị an toàn, hiệu quả và làm giảm nguy cơ đột quỵ não ở bệnh nhân có hẹp động mạch cảnh. Phương pháp này đã được áp dụng tại một số trung tâm phẫu thuật mạch máu lớn với kết quả khả quan.

Mục tiêu nghiên cứu của chúng tôi nhằm đánh giá hiệu quả của phẫu thuật bóc lớp trong động mạch cảnh trong điều trị hẹp động mạch cảnh ngoài sọ.

Đối tượng nghiên cứu: Toàn bộ bệnh nhân bị hẹp động mạch cảnh được phẫu thuật bóc lớp trong động mạch cảnh tại bệnh viện Thống nhất, Bệnh viện Đại học Y dược TP Hồ Chí Minh và Bệnh viện Pháp Việt trong thời gian 10 năm từ 2004 - 2014.

Phương pháp nghiên cứu: Tiến cứu mô tả hàng loạt ca. Đánh giá các đặc điểm về tuổi, giới tính, biểu hiện lâm sàng. Chẩn đoán thương tổn dựa trên siêu âm Duplex, Chụp cắt lớp điện toán động mạch và hoặc $\mathrm{X}$ quang động mạch.

Phẫu thuật bóc lớp trong động mạch cảnh và phục hồi động mạch cảnh có miếng vá PTFE hoặc bóc lớp trong động mạch cảnh kiểu lộn ngược.

Đánh giá tỉ lệ tử vong, tỉ lệ đột quỵ não do phẫu thuật, sau mổ 1 năm, 5 năm. Tần suất tái hẹp động mạch cảnh sau mổ 1 năm, 5 năm.

Kết quả: Trong thời gian 10 năm 2004 đến 2014 chúng tôi đã thực hiện 500 phẫu thuật bóc lớp trong động mạch cảnh. Tuổi trung bình là $70.2(49$ - 92) Tỉ lệ nam/nữ là $4: 1$. Có $54,8 \%$ các trường hợp có tai biến mạch máu não mới hoặc cũ. 12,4\% trường hợp tổn thương cả 2 động mạch cảnh. Tất cả các trường hợp đều được gây mê nội khí quản. Động mạch cảnh được bóc lớp trong và phục hồi với miếng vá PTFE hoặc bóc lộn vỏ động mạch cho các trường hợp có tổn thương động mạch cảnh trong. 3 bệnh nhân tử vong trong 1 tháng sau mổ; 4 trường hợp đột quỵ não trong mổ 1 tháng.

Theo dõi từ 1 - 10 năm cho thấy sau 1 năm có 3 trường hợp tử vong, 1 trường hợp đột quỵ não, 6 trường hợp hẹp tái phát $>50 \%$; sau 5 năm ước tính tỉ lệ tử vong $2,0 \%$, đột quỵ não $1,4 \%$, hẹp tái phát > $50 \%$ là $1,8 \%$.

Kết luận: Phẫu thuật bóc lớp trong động mạch cảnh là phương pháp điều trị hiệu quả và an toàn cho hẹp động mạch cảnh ngoài sọ, tỉ lệ tái hẹp thấp, giảm nguy cơ đột quỵ và tử vong do hẹp động mạch cảnh.

*Tù khóa: Hẹp động mạch cảnh, đột quỵ não, phẫu thuật bóc lớp trong động mạch cảnh. ${ }^{*}$

\section{CAROTID ENDARTERECTOMY: 500 CASES EXPERIENCES}

\section{SUMMARY}

Background: Carotid endarterectomy is effective method for preventing stroke due to carotid stenosis. Carotid endarterectomy has been performed in Viet nam since 2002 .

The purpose of this study was review our experience on carotid endarterectomy in Ho Chi Minh city.

Methods: Prospective. Eveluate the clinical characteristics of stenosis of the carotid. Diagnosis was based on Duplex scanning, CT Angiography (CTA) and/or angiography. Carotid endarterectomy were performed for all of cases with conventional carotid endarterectomy or Eversion carotid endarterectomy.

Primary outcomes are mortality rates, stroke rates, restenosis at 1 month, 1 year and 5 years after operation.

Result: From 2004 to 2014, 500 carotid endarterectomy were done in Thong nhat hospital, Univerrsity Medical Hospital at HCMC and FV

*Bệnh viện Thống nhất.

** Bệnh viện Đại học Y Duoọc TP HCM

Nguoòi chịu trách nhiệm khoa học: PGS.TS. Đỗ Kim Quế

Ngày nhận bài: 10/01/2016 - Ngày Cho Phép Đăng: 24/02/2016

Phản Biện Khoa học: PGS.TS. Đặng Ngọc Hùng GS.TS. Lê Ngọc Thành 
hospital. Mean age is 70.2 range 46 - 92, male : female ratio is $4: 1.54,8 \%$ of cases had stroke before, $12,4 \%$ of cases had bilateral carotid stenosis. Atherosclerosis are the cause of all cases. All of patients were diagnosed by Duplex scan and CTA.

No procedure-related morbidity or mortality was observed. $03(0,6 \%)$ patients died by AMI, and pneumonia in 1 month postoperative period, 04 $(0,8 \%)$ stroke in 1 month after operation. After 1-10 years follow up, 5 years mortality rates is $2,0 \%$, stroke rates is $1,4 \%$, restenosis is $1,8 \%$. 2 patients died after 2 years and 5 years due to cancer, 2 had stroke, 6 recurrent stenosis.

Conclusions: Carotid endarterectomy is the safe and effective methods for preventing stroke due to stenosis of carotid artery.

\section{1. ĐẠTT VẤN ĐỀ:}

Phẫu thuật bóc lớp trong động mạch cảnh được De Bakey thực hiện thành công lần đầu tiên năm 1953. Sau đó năm 1985 Kieny đưa ra phương pháp bóc lớp trong động mạch cảnh kiểu lộn vỏ động mạch nhằm rút ngắn thời gian kẹp động mạch cảnh và giảm tỉ lệ hẹp tái phát.

Phẫu thuật bóc lớp trong động mạch cảnh là phẫu thuật mạch máu được thực hiện nhiều nhất tại Mỹ, Pháp và các nước phát triển, phẫu thuật này đã được áp dụng rộng rãi tại các trung tâm phẫu thuật mạch máu cho những trường hợp hẹp động mạch cảnh ngoài sọ $>60 \%$ không triệu chứng lâm sàng, và hẹp $>50 \%$ có triệu chứng thiếu máu não.

Phẫu thuật động mạch cảnh đã được thực hiện tại bệnh viện Thống Nhất từ năm 2003 và là một trong các bệnh viện thực hiện phẫu thuật bóc lớp trong động mạch cảnh nhiều nhất trong khu vực. Hiện nay nhiều bệnh viện trong cả nước đã triển khai phẫu thuật bóc lớp trong động mạch cảnh như bệnh viện Việt Đức, bệnh viện Bạch Mai, bệnh viện Trung ương Huế, bệnh viện Chợ rẫy, bệnh viện Đại học Y dược TP Hồ Chí Minh. Tuy nhiên chưa nhiều báo cáo đánh giá kết quả dài hạn phẫu thuật bóc lớp trong động mạch cảnh. [2, 4, 7]

Hẹp động mạch cảnh là một trong những nguyên nhân chính gây đột quỵ não. Theo báo cáo của Mayo Clinic $18 \%$ các trường hợp đột quỵ não có tổn thương các động mạch lớn trong và ngoài sọ. Tần suất hẹp động mạch cảnh $>60 \%$ ở những bệnh nhân đột quy lần đầu trong nghiên cứu NOMASS [44] là 7\%. Trong nghiên cứu Framingham [23], 9\% nam và $7 \%$ nữ có hẹp động mạch cảnh $>50 \%$. Mức độ hẹp động mạch cảnh liên quan mật thiết với tần suất của đột quy. Theo Cinà $\mathrm{CS}$ và cộng sự [21], 33\% những trường hợp hẹp động mạch cảnh từ 80 - 99\% có cơn thiếu máu não hoặc nhũn não do lấp mạch trong khi đó tỉ lệ này chỉ xuất hiện ở $0.4 \%$ ở những bệnh nhân hẹp động mạch cảnh dưới $80 \%$.

Các nghiên cứu về đột quỵ não đã được nhiều trung tâm trong nước thực hiện trong những năm vừa qua. Tần suất đột quỵ do thiếu máu nuôi ngày càng gia tăng. Theo Lê văn Thành, tần suất đột quỵ não ở TP Hồ Chí Minh và các tỉnh phía Nam là 415/100.000 dân trong đó tỉ lệ đột quỵ não mới là 141/100.000 dân. Tỉ lệ tử vong do đột quỵ não là 37/100.000 dân. Ước tính ở Việt Nam mỗi năm có khoảng 199.444 trường hợp đột quỵ não mới.

Phẫu thuật bóc lớp trong động mạch cảnh cho những bệnh nhân hẹp từ 70 - 99\% làm giảm nguy cơ đột quỵ não $17 \%$. Hơn nữa phẫu thuật bóc lớp trong động mạch cảnh là một phẫu thuật an toàn tỉ lệ tử vong và biến chứng dưới $5 \%$ ở những bệnh nhân có triệu chứng và dưới $3 \%$ ở những bệnh nhân không có triệu chứng. $[8,21,48]$ Do đó việc phát hiện sớm hẹp động mạch cảnh ngoài sọ và điều trị đúng đắn sẽ góp phần làm giảm nguy cơ tai biến mạch máu não.

Chúng tôi tiến hành nghiên cứu này nhằm mục tiêu đánh giá kết quả trước mắt và lâu dài của phẫu thuật bóc lớp trong động mạch cảnh trong điều trị hẹp động mạch cảnh ngoài sọ.

\section{2. ĐỐI TƯợNG VÀ PHƯƠNG PHÁP NGHIÊN CÚU \\ 2.1 Đối tương nghiên cứu:}

Tất cả những trường hợp hẹp động mạch cảnh ngoài sọ được điều trị phẫu thuật tại bệnh viện Thống nhất, bệnh viện Đại học $\mathrm{Y}$ dược TP Hồ Chí Minh và bệnh viện Pháp Việt trong thời gian 10 năm từ năm 2004 tới năm 2014.

2.2 Phưong pháp nghiên cứu: Tiền cứu mô tả cắt dọc. 
- Đăc điểm bênh nhân:

○ Tất cả bệnh nhân được đánh giá các yếu tố: tuổi, giới, hút thuốc lá, rối loạn lipid máu.

○ Các dấu hiệu lâm sàng: Tai biến mạch máu não, thiếu máu não thoáng qua, âm thổi vùng động mạch cảnh.

- Chẩn đoán múc độ hẹp dựa trên: Siêu âm Duplex, Chụp cắt lớp điện toán động mạch (CTA) và/ hoặc X quang động mạch.

- Chi định phẫu thuạt bóc lớp trong động mạch cảnh cho các trường hợp: chứng.

○ Hẹp động mạch cảnh trên $70 \%$ không có triệu

○ Hẹp $>50 \%$ nhưng có loét trên mảng xơ vữa và có triệu chứng.

- Phuoong pháp phẫu thuật:

○ Tất cả bệnh nhân đều được gây mê nội khí quản.

○ Bóc lớp trong động mạch cảnh kiểu lộn ngược vỏ động mạch hoặc mở dọc động mạch kinh điển có dùng miếng vá PTFE khâu phục hồi động mạch.

- Đánh giá kết quả:

○ Kết quả phẫu thuật:

- Đánh giá tỉ lệ tử vong, phân tích nguyên nhân tử vong

- Tỉ lệ các biến chứng: đột quỵ não, và các biến chứng khác.

○ Kết quả lâu dài: đánh giá tỉ lệ tử vong, đột quỵ não, theo dõi định kỳ 1 tháng, 3 tháng và mỗi 6 tháng sau mổ.

- Sự cải thiện các triệu chứng lâm sàng,

- siêu âm Duplex kiểm tra.

- Đánh giá tỉ lệ tái hẹp, tỉ lệ đột quỵ tái phát.

\section{KẾT QUẢ NGHIÊN CÚU:}

3.1 Đặc điểm bệnh nhân: Trong thời gian 10 năm chúng tôi thực hiện phẫu thuật cho 500 trường hợp hẹp động mạch cảnh ngoài sọ trong đó 386 bệnh nhân là nam. Tuổi trung bình: $70.2+10.3$ trong đó trẻ nhất là 49 và lớn tuổi nhất là 92 tuổi, $62.5 \%$ bệnh nhân trên 70 tuổi.

\section{2 Đặc điểm lâm sàng:}

Cao huyết áp ghi nhận ở 421 trường hợp.

Tiền sử tai biến mạch máu não ghi nhận ở 274 trong số 200 trường hợp, trong đó 82 trường hợp có nhũn não mới trong vòng 6 tuần.

Âm thổi vùng động mạch cảnh phát hiện ở 224 trường hợp.

Dấu hiệu thiếu máu não thoáng qua: 215 bệnh nhân.

Bảng 1: Đặc điểm lâm sàng

\begin{tabular}{|l|c|c|}
\hline \multicolumn{1}{|c|}{ Đặc điểm lâm sàng } & $\begin{array}{c}\text { Số trường } \\
\text { hợp }\end{array}$ & \% \\
\hline Cao huyết áp & 421 & 84,2 \\
\hline Di chứng tai biến mạch máu não & 192 & 38,4 \\
\hline Tai biến mạch máu não mới & 82 & 16,4 \\
\hline Cơn thiếu máu não & 251 & 50,2 \\
\hline Âm thổi vùng động mạch cảnh & 224 & 44,8 \\
\hline
\end{tabular}

3.3 Các phương pháp chẩn đoán hình ảnh học:

Siêu âm Duplex động mạch cảnh được thực hiện ở tất cả các trường hợp.

Chụp cắt lớp điện toán động mạch được thực hiện ở 470 trường hợp.

MRA được thực hiện cho 65 trường hợp.

$\mathrm{X}$ quang động mạch được thực hiện cho 27 trường hợp.

\subsection{Vị trí động mạch hẹp:}

Trong 500 trường hợp hẹp/tắc động mạch cảnh đã phẫu thuật của chúng tôi có 82 trường hợp có tổn thương cả 2 động mạch cảnh, 418 trường hợp hẹp 1 động mạch cảnh với phân bố:

Bảng 2: Vị trí đông mach hep

\begin{tabular}{|l|c|c|}
\hline \multicolumn{1}{|c|}{ Vị trí hẹp } & Số trường hộp & \% \\
\hline Hai động mạch & 82 & 16,4 \\
\hline Một động mạch & 418 & 83,6 \\
Động mạch cảnh P & 198 & 47,4 \\
Động mạch cảnh T & 220 & 52,6 \\
\hline
\end{tabular}

\subsection{Mức độ hẹp:}

Chúng tôi đánh giá mức độ hẹp dựa trên các phương pháp chẩn đoán hình ảnh học có đối chiếu với kết quả trong mổ.

Bảng 3: Mức độ hẹp.

\begin{tabular}{|l|c|c|}
\hline \multicolumn{1}{|c|}{ Mức độ hẹp } & Số trường họ̣p & \% \\
\hline $50-80 \%$ & 42 & 8,4 \\
\hline $80-99 \%$ & 424 & 84,8 \\
\hline $100 \%$ & 34 & 6,8 \\
\hline
\end{tabular}




\subsection{Phương pháp phẫu thuật:}

Phẫu thuật bóc lớp trong động mạch cảnh được áp dụng cho tất cả các trường hợp, 456 trường hợp có dùng miếng vá PTFE tái tạo lại động mạch cảnh, 4 trường hợp ghép ống PTFE cảnh gốc - phình cảnh. 74 trong số 500 trường hợp được đặt shunt tạm chiếm tỉ lệ $14,8 \%$.

Bảng 4: Phương pháp phẫu thuật.

\begin{tabular}{|l|c|c|}
\hline \multicolumn{1}{|c|}{ Phuong pháp phẫu thuật } & $\begin{array}{c}\text { Số truò̀ng } \\
\text { họp }\end{array}$ & \% \\
\hline $\begin{array}{l}\text { Bóc lớp trong động mạch, đặt } \\
\text { miếng vá động mạch. }\end{array}$ & 456 & 91,2 \\
\hline $\begin{array}{l}\text { Bóc lớp trong động mạch, ghép } \\
\text { ông động mạch nhân tạo. }\end{array}$ & 4 & 0,8 \\
\hline $\begin{array}{l}\text { Bóc lớp trong động mạch kiểu } \\
\text { lộn ngược. }\end{array}$ & 40 & 8,0 \\
\hline
\end{tabular}

\subsection{Kết quả điều trị:}

Kết quả ngắn hạ: 03 trường hợp tử vong trong 30 ngày sau mổ do viêm phổi suy hô hấp chiếm tỉ lệ $0,6 \%$. 04 trường hợp bị nhồi máu não sau mổ chiếm tỉ lệ $0,8 \%$.

Kết quả lâu dài: Theo dõi từ 1 tới 10 năm.

Cải thiện triệu chứng lâm sàng ghi nhận ở các trường hợp có biểu hiện thiếu máu não trước mổ.

Kết quả siêu âm Duplex kiểm tra sau mổ 1 tháng cho thấy không còn hẹp động mạch cảnh ở tất cả các trường hợp.

Sau 1 năm, có 3 bệnh nhân tử vong, một bệnh nhân bị đột quỵ não, 6 bệnh nhân bị hẹp tái phát $>50 \%$.

Sau 5 năm tỉ lệ bênh nhân còn sống đạt $90,2 \%$, Tỉ lệ bệnh nhân không đột quỵ tái phát đạt 86,8\%.

\section{BÀN LUẬN:}

Hẹp động mạch cảnh ngoài sọ là nguyên nhân chính gây ra cơn thiếu máu não cục bộ và nhũn não. Phát hiện sớm và điều trị thích hợp sẽ giúp bệnh nhân hồi phục tốt và giảm nguy cơ nhũn não. Phẫu thuật bóc lớp trong động mạch cảnh ở bệnh nhân chưa đột quỵ sẽ làm giảm nguy cơ đột quỵ và tàn phế cho bệnh nhân.

Hẹp động mạch cảnh thường thấy ở bệnh nhân lớn tuổi, trong nghiên cứu của chúng tôi tuổi trung bình của bệnh nhân là 70,2, trong đó $62.5 \%$ bệnh nhân trên 70 tuổi. Điều này cũng tương tự các nghiên cứu khác trong y văn.
Đa số bệnh nhân của chúng tôi nhập viện ở giai đoạn muộn khi đã có nhũn não mới hoặc đã thành di chứng với tỉ lệ $54,8 \%$. So với các nghiên cứu tại Âu Mỹ, tỉ lệ phẫu thuật hẹp động mạch cảnh ở bệnh nhân đã có đột quỵ của chúng tôi cao hơn nhiều. Tuy nhiên so với giai đoạn trước 2005 tỉ lệ phẫu thuật hẹp động mạch cảnh khi chưa đột quỵ đã tăng rõ rệt. (Bảng 5)

Bảng 5: Đặc điểm bệnh nhân.

\begin{tabular}{|l|c|c|c|c|}
\hline & $\begin{array}{c}\text { ECST } \\
{[\mathbf{3 8}]}\end{array}$ & $\begin{array}{c}\text { NASCET } \\
{[\mathbf{3 2}]}\end{array}$ & $\begin{array}{c}\text { VACSP } \\
{[\mathbf{4 8}]}\end{array}$ & $\begin{array}{c}\text { Đố Kim } \\
\text { Quế [6] }\end{array}$ \\
\hline Thời gian nghiên cứu & $\begin{array}{c}1981- \\
1995\end{array}$ & $\begin{array}{c}1987- \\
1997\end{array}$ & $\begin{array}{c}1988- \\
1991\end{array}$ & $\begin{array}{c}2004- \\
2012\end{array}$ \\
\hline Số trung tâm nghiên cứu & 97 & 106 & 16 & 1 \\
\hline Thiếu máu não thoáng qua & & 38 & 38 & 57.2 \\
\hline Đột quỵ & & 43 & 24 & 51.3 \\
\hline $\begin{array}{l}\text { Hẹp động mạch cảnh đối } \\
\text { bên > 50\% }\end{array}$ & 6 & 4 & & 18.3 \\
\hline Tuối trung bình & 63 & 65 & 66 & 72.2 \\
\hline Nam & 72 & 69 & 100 & 79.2 \\
\hline Hút thuốc lá & 52 & 31 & 92 & 70.9 \\
\hline Tiếu đường & 12 & 21 & 30 & 37.9 \\
\hline
\end{tabular}

Siêu âm Duplex động mạch cảnh là phương pháp chẩn đoán hình ảnh rất có giá trị trong chẩn đoán hẹp động mạch cảnh. Tất cả các trường hợp hẹp động mạch cảnh trong nghiên cứu của chúng tôi đều được làm siêu âm Duplex động mạch cảnh và cột sống với kết quả chính xác cao. Tại nhiều trung tâm lớn người ta có thể phẫu thuật dựa trên kết quả Duplex động mạch cảnh. Tuy nhiên độ nhậy và độ chuyên biệt của phương pháp này tùy thuộc rất nhiều vào trình độ của bác sĩ siêu âm. [13, 18, 22]

Filis và cộng sự [22] nghiên cứu về siêu âm duplex đánh giá mức độ hẹp động mạch cảnh trên 163 bệnh nhân với 326 động mạch cảnh được khảo sát. Kết quả nghiên cứu cho thấy có sự phù hợp cao giữa Duplex và chụp $\mathrm{X}$ quang động mạch cảnh với hệ số tương quan là 0.96 . Tác giả đã đưa ra tiêu chuẩn chẩn đoán mới dựa vào vận tốc dòng máu.

Theo Fillis và cộng sự, [22] siêu âm Duplex động mạch cảnh có giá trị rất tốt cho những trường hợp hẹp dưới $50 \%$ hoặc hẹp trên $90 \%$. Với những trường hợp hẹp từ $50-89 \%$ độ nhây cảm và độ chuyên biệt có thấp hơn những vẫn đạt trên $80 \%$.

Chụp cắt lớp điện toán động mạch cảnh là một phương pháp chẩn đoán hình ảnh ít xâm lấn có độ 
nhậy và độ đặc hiệu cao có thể thay thế chụp X quang động mạch. Josephson và cộng sự [29] nghiên cứu so sánh giữa chụp cắt lớp điện toán động mạch và $\mathrm{x}$ quang động mạch cho thấy độ nhậy $100 \%$ và độ chuyên $63 \%$, giá trị tiên đoán âm của hẹp động mạch cảnh $<70 \%$ đạt $100 \%$. Độ chính xác của chụp cắt lớp điện toán động mạch tùy thuộc vào kinh nghiệm bác sĩ đọc kết quả, độ phân giải của máy chụp cắt lớp, lượng thuốc cản quang và kỹ thuật tiêm thuốc, ghi hình ảnh. Răng giả kim loại, các clip vùng cổ, bệnh nhân béo phì không hợp tác tốt cử động trong khi ghi hình ảnh sẽ ảnh hưởng tới kết quả chụp cắt lớp điện toán động mạch. [2, 28, 29]

Chụp cắt lớp điện toán động mạch cảnh còn cho phép xác định tổn thương động mạch trong sọ, phình động mạch đi kèm hoạc các tổn thương khác của não. Không giống như Duplex và cộng hưởng từ mạch máu, chụp cắt lớp điện toán động mạch cung cấp hình ảnh thật của lòng động mạch. Với các máy chụp cắt lớp đa lát cắt hình ảnh thu được chính xác hơn. Với kỹ thuật dựng hình cấu trúc mạch máu, hình ảnh giải phẫu của động mạch có thể thấy rõ. Với các máy chụp cắt lớp điện toán hiện đại nhiều đầu dò và nhiều lát cắt trên 320 lát cắt sẽ rút ngắn thời gian chụp, cần ít thuốc cản quang hơn mà vẫn cho hình ảnh chụp rõ nét và độ chính xác cao.

Theo Cinà và cs. [21] tổng hợp 23 nghiên cứu về động mạch cảnh tại châu Âu và bắc Mỹ với 6078 bệnh nhân trong đó 3777 bệnh nhân được phẫu thuật bóc lớp trong động mạch cảnh. Tác giả kết luận phẫu thuật bóc lớp trong động mạch cảnh cho những trường hợp hẹp trên $70 \%$ sẽ làm giảm nguy cơ đột tử và nhũn não $48 \%$, và ở những trường hợp hẹp $50-69 \%$ làm giảm nguy cơ đột tử và tai biến mạch máu não $27 \%$.

Trường hợp bệnh nhân đã có nhũn não do hẹp động mạch cảnh thì chỉ định phẫu thuật nhằm làm giảm nguy cơ đột quỵ tái phát. Thời điểm phẫu thuật sau đột quỵ được đa số các tác giả thống nhất là 6 tuần. Tuy nhiên một số nghiên cứu gần đây cho thấy phẫu thuật sớm ở những trường hợp có hồi phục tốt trong vòng 2 tuần không làm tăng tỉ lệ tử vong và biến chứng nhưng giảm nguy cơ tái nhồi máu não. [19, 25, 31]

Về phương pháp vô cảm chúng tôi chọn lựa phương pháp mê nội khí quản cho tất cả các trường hợp. Hiện tại có các trung tâm phẫu thuật bóc lớp trong động mạch cảnh với gây tê vùng nhằm đánh giá tình trạng tri giác bệnh nhân khi phẫu thuật.
Kỹ thuật phục hồi động mạch cảnh sau khi bóc lớp trong với miếng vá động mạch hoặc trực tiếp tùy thuộc kích thước động mạch cảnh. Trong nghiên cứu của chúng tôi miếng vá mạch máu được sử dụng cho 456/500 trường hợp.

Bóc lớp trong động mạch với kỹ thuật lộn ngược vỏ động mạch rút ngắn thời gian kẹp động mạch cảnh và không cần dùng miếng vá động mạch cho kết quả tốt trong 40 trường hợp đã tiến hành trong nghiên cứu này. $[10,19,41]$

Phẫu thuật bóc lớp trong động mạch cảnh là một phương pháp hiệu quả và an toàn, tỉ lệ tử vong và biến chứng thấp. Theo hầu hết các nghiên cứu lớn tỉ lệ này khoảng $0-3 \%$. Trong nghiên cứu của chúng tôi có 3 trường hợp tử vong tử vong với tỉ lệ $0,6 \%$, tỉ lệ đột quỵ trong mổ là $0,8 \%$.

Kết quả theo dõi lâu dài cho thấy hiệu quả tốt của phẫu thuật trong việc cải thiện tình trạng thiếu máu não qua lâm sàng và siêu âm Duplex mạch máu. Trong nghiên cứu này sau 1 năm và 5 năm tỉ lệ sống là $98,8 \%$ và $90,2 \%$. Tỉ lệ đột quỵ não sau 1 năm và sau 5 năm là $1 \%$ và $3,6 \%$.

\section{KẾT LUẬN}

Qua nghiên cứu 500 trường hợp hẹp động mạch cảnh đã được điều trị phẫu thuật bóc lớp trong động mạch cảnh, chúng tôi rút ra các nhận xét:

Đa số hẹp động mạch cảnh xảy ra ở bệnh nhân nam lớn tuổi có hút thuốc lá. Tỉ lệ bệnh đã bị đột quỵ cao $(54,8 \%)$.

Phẫu thuật bóc lớp trong động mạch cảnh với gây mê là một phương pháp phẫu thuật an toàn và hiệu quả trong điều trị hẹp động mạch cảnh. Tỉ lệ tử vong, tỉ lệ tái hẹp thấp, tần suất đột quy não sau phẫu thuật 5 năm là $3,6 \%$.

\section{TÀI LIẸU THAM KHẢO}

\section{Tiếng Việt}

1. Đỗ Kim Quế, Chung Giang Đông. (2014). Kết quả phẫu thuật cầu nối động mạch vành trong điều trị hẹp nhiều nhánh động mạch vành ở bệnh nhân có hẹp nặng động mạch cảnh. Tạp chí Y học Thành phố Hồ Chí Minh. 18 (3): 383 - 388.

2. Đỗ Kim Quế. (2004). Chẩn đoán và điều trị ngoại khoa hẹp động mạch cảnh ngoại sọ. Y học thực hành. 491: 405 - 409. 
3. Đỗ Kim Quế. (2008). Phẫu thuật bóc lớp trong động mạch cảnh 2 bên. Y học Việt Nam, 2(352): 262-74.

4. Đỗ Kim Quế. (2011). Kết quả ngắn và trung hạn phẫu thuật bóc lớp trong động mạch cảnh. Tạp chí Y học Thành phố Hồ Chí Minh. 15(1): 434 - 439.

5. Đỗ Kim Quế (2011). Phẫu thuật Bóc lớp trong động mạch cảnh: kinh nghiệm 5 năm. Tạp chí Y học Thành phố Hồ Chí Minh. 15(2): 248 - 252.

6. Đỗ Kim Quế, Chung Giang Đông. (2012). Điều trị ngoại khoa hẹp động mạch cảnh ngoài sọ: kinh nghiệm 200 trường hợp. Tạp chí Y học Thành phố Hồ Chí Minh. 16(4): 256 - 261.

7. Lê Nữ Hòa Hiệp, Nguyễn Thế Hiệp. (2003) Điều trị ngoại khoa hẹp động mạch cảnh ngoài sọ nhân ba trường hợp tại bệnh viện nhân dân Gia định. Y học TP. Hồ Chí Minh. 7 (phụ bản 2):92- 96.

\section{Tiếng Anh}

8. AbuRahma AF, Robinson PA, Mullin DA, Holt SM, Herzotg TA, Mowery NT. (2000) Frequency of postoperative cartid duplex serveillance and type of closure: Results from randomized trial. Vasc Surg. 32:1043-51.

9. Back MR, Wilson JS, Rushing G, Stordahl N, Linden C, et al. (2000) Magnetic resonance angiography is an accurate imaging adjunct to Duplex ultrasound in patient selection for carotid endarterectomy. J Vasc Surg 32:429-41.

10. Ballotta E, Meneghetti G, Mananra R. (2007). Long-term survival and stroke-free survival after eversion carotid endarterectomy for asymptomatic severe carotid stenosis. J Vasc Surg. 33: 678-83

11. Ballotta R, Luzzani L, Carugatti C. (2006). Routine shunting is a safe and reliable method of cerebral protection during carotid endarterectomy. Ann Vasc Surg, 12: 243 - 46

12. Bertoletti G, Varroni A, Misuraca M, Massucci M, Pacelli A, et al. (2013) Carotid Artery Diameters, Carotid Endarterectomy Techniques and Restenosis. J Vasc Med Surg 1: 114

13. Bluth EI, Sunshine JH, Lyons JB, et al. (2000) Power Doppler imaging: initial evaluation as a screening examination for carotid artery stenosis. Radiology. 215:791-800.
14. Bonati LH, Jongen LM, Haller S, et al. (2010). New ischemic brain lesions on MRI after stenting or endarterectomy for symptomatic carotid stenosis: a substudy of the International Carotid Stenting Study (ICSS). Lancet Neurol. 9:353-62.

15. Broderick J, Brott T, Kothari R, et al. (1998). The Greater Cincinnati/Northern Kentucky Stroke Study: preliminary first-ever and total incidence rates of stroke among blacks. Stroke. 29:415-21.

16. Brott TG, Hobson RW, Howard G, et al. (2010). Stenting versus endarterectomy for treatment of carotid-artery stenosis. N Engl J Med. 363:11-23.

17. Cinà CS, Clase CM, Haynes BR. (1999). Refining the indications for carotid endarterectomy in patients with symptomatic carotid stenosis: A systemic review. J Vasc Surg 30:606-18.

18. Corriveau MM, Johnston KW. (2004). Interobsever variability of carotid Doppler peak velocity measurements among technologists in an ICVLaccredited vascular laboratory. Vasc Surg. 39:735-41.

19. Demirel S, Attigah N, Bruijnen H, Ringleb P, Eckstein H, Fraedrich G, Bo"ckler D (2012). Multicenter Experience on Eversion versus Conventional Carotid Endarterectomy in Symptomatic Carotid Artery Stenosis. Stroke 43:1865-1871.

20. Eckstein HH, Ringleb $\mathrm{P}$, Allenberg JR, et al. (2008). Results of the Stent-Protected Angioplasty versus Carotid Endarterectomy (SPACE) study totreat symptomatic stenoses at 2 years: a multinational, prospective, randomised trial. Lancet Neurol. 7:893-902.

21. Executive Committee for the Asymptomatic Carotid Atherosclerosis Study. (1995). Endarterectomy for asymptomatic carotid artery stenosis.JAMA.273:1421-8.

22. Filis KA, Arko FR, Johnson BL, Pipinos II, Harris EJ, Oncott C, Zarins CK. (2002). Duplex ultrasound criteria for defining the severity of carotid stenosis. Ann Vasc Surg 416: 213-221.

23. Fine-Edelstein JS, Wolf PA, O'Leary DH, et al. (1994). Precursors of extracranial carotid atherosclerosis in the Framingham Study. Neurology. 44:1046 -50. 